\title{
Effect of life style (exercise and nutrition) on occurrence of breast cancer in women: A retrospective study in Babylon governorate
}

\author{
Najat Hamza Hassanª \& Rabea M Alib
}

\begin{abstract}
Objective To identify the effect of exercise and nutrition on breast cancer occurrence and to find the relationship between life style and some demographic and reproductive variables.

Methods A retrospective study (case control study) of a purposive sample of 400 women; 200 women diagnosed with breast cancer visited the Merjan Teaching Hospital Oncology Cancer Center in Babylon Governorate as a study group and 200 women free of breast cancer as a control group. An assessment tool was constructed for the purpose of the study. It comprised of socio-demographic data, reproductive data, information related to breast cancer (stage, side, period, family history) and information related to their life style: exercise (5 items) and nutrition (14 items) of 10 years previous breast cancer occurrence, physical measurements for measuring obesity and overweight (BMI) as well as medical records to explain in the stage of breast cancer and other details which may be assisting this study Data were collected from 4 May 2013 to 4 July 2013. Analysis of data was performed through the application of descriptive and inferential statistical data analysis approach.

Results The study demonstrates that the highest percentage (39.5\%) of study sample was in age group 50-54 years in comparison with the other age groups for both the study and control groups. There was a high significant difference at $\mathrm{P}<0.01$ between the life aspects (exercise and nutrition) and breast cancer in women while no relationship between life aspects and demographical and reproductive variables except with interval between pregnancies and duration of contraception of study group was noted.

Conclusion Establishing an activation media and Ministry of Health role for guiding women and their families about the importance of exercise and healthy nutrition which contributes to reducing the incidence of breast cancer occurrence and the importance of early detection of breast cancer

Keywords life style, breast cancer, women, retrospective study
\end{abstract}

\section{Introduction}

The two most important parts of physical health involve exercise and nutrition. These two go hand-in-hand. Not fueling the body with proper nutrition negates many of the benefits of exercise and vice versa. ${ }^{1}$ Diet and exercise have a direct impact on the quality of life of people in their later years. According to the National Institute on Ageing, regular physical exercise and proper nutrition can help people remain independent for long. This healthy lifestyle can keep a variety of age-related conditions and diseases at bay permanently. While genes play a significant role in the life span of people, proper nutrition and regular exercise directly affects how well they live. According to the American Geriatrics Society, a lifetime of healthy living may be the most beneficial to healthy ageing, but it is never too late to begin eating well and exercising regularly. Eat foods of a variety of colors and those rich in omega-3 fatty acids to remain strong. Stay physically fit with regular exercise and reduce the risk of falling. ${ }^{2}$ Cancer is a disease that is caused by both genetic and environmental factors. Some women are born with a genetic mutation that dramatically increases their risk of developing breast cancer. But for all women, including women with a genetic mutation, environmental factors such as diet, exercise and chemical exposures affect genes in ways that determine whether cancer actually develops. ${ }^{3}$ Researchers found more than 3000 women with and without breast cancer, those who exercised during their childbearing years were less likely to develop cancer after menopause. The effects of physical activity were strong among postmenopausal women. Women may significantly reduce their risk for breast cancer by exercising a couple hours each day. A new study found that even mild physical activity like walking reduced risk for the disease that strikes 227000 new women each year. ${ }^{4}$ Diet is thought to be partly responsible for about $30 \%-40 \%$ of all cancers. But diet alone is unlikely to be the "cause" or "cure" of cancer. Although more research needs to be done on diet and breast cancer, findings suggest that physical activity, a healthy diet (particularly one low in fat and high in vegetables and fiber) and a healthy weight can help reduce the risk of breast cancer or its reoccurrence. ${ }^{5}$

\section{Materials and Methods}

A retrospective study (a case control study) was conducted on the effect of life style on occurrence of breast cancer in women. A purposive sample of 400 women; 200 diagnosed with breast cancer as a study group and 200 the control group which was free from breast cancer or any other types of cancer past and present, were collected from different districts within Babylon Governorate and looks back retrospectively for previous 10 years. The questionnaire was designed for the purpose of the study. It comprised of four parts: socio-demographic data such as mother's age, body mass index (BMI), marital status, family income through previous 10 years; reproductive data such as gravidity, parity, age at menarche, age at first pregnancy, pregnancy interval, menopausal age, age at last menstrual period, reproductive age, breast feeding, duration of contraceptive pills;

a Technical Institute, Al-Furat Al-Awsat Technical University, Karbala, Iraq.

${ }^{b}$ Maternity and Child Health Nursing, College of Nursing, University of Baghdad, Baghdad, Iraq.

Correspondence to Najat Hamza Hassan (noorhuda4@yahoo.com)

(Submitted: 08 December 2014 - Revised version received: 24 January 2015 - Accepted: 12 February 2015 - Published online: Winter 2015) 
information related to woman's healthy life style exercise which includes 5 items, and the nutrition aspect includes 14 items. These items were rated according to scale (always, sometimes and never), and information related to breast cancer were rated based on stage, side, period and family history of breast cancer (previous 1-10 years). BMI was indicated for measuring obesity and overweight. The investigator measures the current BMI according to WHO categories of BMI in 2002 which are: underweight $=$ $<18.5 \mathrm{~kg} / \mathrm{m}^{2}$; normal weight $=18.5-24.9$ $\mathrm{kg} / \mathrm{m}^{2} ;$ overweight $=25-29.9 \mathrm{~kg} / \mathrm{m}^{2}$; obesity $=30 \mathrm{~kg} / \mathrm{m}^{2}$ or greater. Medical records explain in which stage of breast cancer they are in and other details which may assist this study. For pilot study and reliability of the questionnaire a convenient sample of 20 breast cancer women who attended Merjan Teaching Hospital Oncology Cancer Center in Babylon Governorate for this preliminary study was conducted from 4 May 2013 to 10 July 2013.

The reliability coefficients of the pilot study are 0.973 . The time required for each interview ranged from 20 to 30 min for each women and 5-10 min for measuring the weight and height to estimate the BMI. Statistical data analysis approaches were used in order to analyse and assess the results of the study depended on descriptive data analysis, and inferential data analysis.

\section{Results}

Table 1 shows the distribution of the two samples (study and control) according to their demographic characteristics variables (age groups, marital status, family income) it reported a non significant difference at $\mathrm{P}>0.05$, which indicates that the two independent groups seems from the same population. In addition, BMI reported a highly significant difference at $\mathrm{P}<0.01$, with bad assessment at the study group compared with the control. The age group, 50-54 years, was shown to be the larger group $(39.5 \%)$ in comparison with the other age groups for both the study and control groups. The highest percentages $(44.5 \%)$ of study group were overweight, while $(48.5 \%)$ the control group had normal weight. About $70.5 \%$ of study and $66.5 \%$ of control group were married, $42.5 \%$ and $47 \%$, respectively, in both groups had sufficient family income.
Table 2 shows that the highest percentage of study and control group $38 \%$ and $39 \%$, respectively, were having 3-4 gravida. Regarding parity, 39\% of study group were having 1-2 para, while for control group 33\% of them were having 3-4 para. The highest percentage of both groups were in post-rep. age.
A $62.5 \%$ and $75.5 \%$ of study group and the highest percentage of the users, $33.5 \%$ and $23 \%$, respectively, were using pills.

Table 3 demonstrates the mean of some reproductive variables. The mean age at menarche for study sample was $12.48 \pm 0.81$ years which was lower than

\section{Table 1. Distribution of the studied demographical characteristics variables in the study and control samples with comparisons significant}

\begin{tabular}{|c|c|c|c|c|c|}
\hline $\begin{array}{l}\text { Demographical } \\
\text { characteristics }\end{array}$ & Samples & Groups & No. & $\%$ & $\begin{array}{c}\text { Asymp. Sig. }\left({ }^{*}\right) \\
\text { (2-tailed) }\end{array}$ \\
\hline \multirow{18}{*}{ Age groups } & \multirow{9}{*}{ Study } & $20-24$ & 2 & 1.0 & \multirow{18}{*}{$\begin{array}{c}Z=0.000 \\
P=1.000 \\
N S\end{array}$} \\
\hline & & $25-29$ & 1 & 0.5 & \\
\hline & & $30-34$ & 3 & 1.5 & \\
\hline & & $35-39$ & 4 & 2.0 & \\
\hline & & $40-44$ & 9 & 4.5 & \\
\hline & & $45-49$ & 30 & 15.0 & \\
\hline & & $50-54$ & 79 & 39.5 & \\
\hline & & $55-59$ & 59 & 29.5 & \\
\hline & & $60 \geq$ & 13 & 6.5 & \\
\hline & \multirow{9}{*}{ Control } & $20-24$ & 2 & 1.0 & \\
\hline & & $25-29$ & 1 & 0.5 & \\
\hline & & $30-34$ & 3 & 1.5 & \\
\hline & & $35-39$ & 4 & 2.0 & \\
\hline & & $40-44$ & 9 & 4.5 & \\
\hline & & $45-49$ & 30 & 15.0 & \\
\hline & & $50-54$ & 79 & 39.5 & \\
\hline & & $55-59$ & 59 & 29.5 & \\
\hline & & $60 \geq$ & 13 & 6.5 & \\
\hline \multirow{8}{*}{$\begin{array}{l}\mathrm{BMI} \\
\left(\mathrm{kg} / \mathrm{m}^{2}\right)\end{array}$} & \multirow{4}{*}{ Study } & Underweight & 35 & 17.5 & \multirow{8}{*}{$\begin{array}{c}Z=2.611 \\
P=0.009 \\
H S\end{array}$} \\
\hline & & Normal weight & 68 & 34 & \\
\hline & & Over weight & 89 & 44.5 & \\
\hline & & Obesity & 8 & 4 & \\
\hline & \multirow{4}{*}{ Control } & Underweight & 40 & 20 & \\
\hline & & Normal weight & 97 & 48.5 & \\
\hline & & Over weight & 53 & 26.5 & \\
\hline & & Obesity & 10 & 5 & \\
\hline \multirow{10}{*}{ Marital status } & \multirow{10}{*}{ Control } & Married & 141 & 70.5 & \multirow{10}{*}{$\begin{array}{c}Z=0.900 \\
P=0.368 \\
N S\end{array}$} \\
\hline & & Single & 16 & 8 & \\
\hline & & Widow & 27 & 13.5 & \\
\hline & & Divorced & 14 & 7 & \\
\hline & & Separated & 2 & 1 & \\
\hline & & Married & 133 & 66.5 & \\
\hline & & Single & 18 & 9 & \\
\hline & & Widow & 29 & 14.5 & \\
\hline & & Divorced & 16 & 8 & \\
\hline & & Separated & 4 & 2 & \\
\hline \multirow{6}{*}{ Family income } & \multirow{6}{*}{ Control } & Sufficient & 85 & 42.5 & \multirow{6}{*}{$\begin{array}{c}Z=0.984 \\
P=0.325 \\
N S\end{array}$} \\
\hline & & Barely sufficient & 48 & 24 & \\
\hline & & Not sufficient & 67 & 33.5 & \\
\hline & & Sufficient & 94 & 47 & \\
\hline & & Barely sufficient & 47 & 23.5 & \\
\hline & & Not sufficient & 59 & 29.5 & \\
\hline
\end{tabular}

${ }^{*}$ C.S.: comparisons significant; NS: non sig. at $P>0.05 ;$ HS: highly sig. at $P<0.01$. 
Table 2. Distribution of the studied reproductive variables in the study and control samples with comparisons significant

\begin{tabular}{|c|c|c|c|c|c|}
\hline $\begin{array}{l}\text { Reproductive } \\
\text { characteristics }\end{array}$ & Samples & Groups & No. & Percent & $\begin{array}{c}\text { C.S } \\
\text { P-value }\end{array}$ \\
\hline \multirow{10}{*}{ Gravidity } & \multirow{5}{*}{ Study } & 0 & 30 & 15 & \multirow{10}{*}{$\begin{array}{c}\chi^{2}=1.985 \\
P=0.921 \\
\text { NS }\end{array}$} \\
\hline & & $1-2$ & 54 & 27 & \\
\hline & & $3-4$ & 76 & 38 & \\
\hline & & $5-6$ & 37 & 17.5 & \\
\hline & & 7 and more & 3 & 1.5 & \\
\hline & \multirow{5}{*}{ Control } & 0 & 32 & 16 & \\
\hline & & $1-2$ & 44 & 22 & \\
\hline & & $3-4$ & 78 & 39 & \\
\hline & & $5-6$ & 41 & 20.5 & \\
\hline & & 7 and more & 5 & 2.5 & \\
\hline \multirow{10}{*}{ Parity } & \multirow{5}{*}{ Study } & 0 & 30 & 15 & \multirow{10}{*}{$\begin{array}{c}\chi^{2}=2.588 \\
P=0.858 \\
\text { NS }\end{array}$} \\
\hline & & $1-2$ & 78 & 39 & \\
\hline & & $3-4$ & 62 & 31 & \\
\hline & & $5-6$ & 28 & 14 & \\
\hline & & 7 and more & 2 & 1 & \\
\hline & \multirow{5}{*}{ Control } & 0 & 32 & 16 & \\
\hline & & $1-2$ & 64 & 32 & \\
\hline & & $3-4$ & 66 & 33 & \\
\hline & & $5-6$ & 34 & 17 & \\
\hline & & 7 and more & 4 & 2 & \\
\hline \multirow{4}{*}{ Reproductive age } & \multirow{2}{*}{ Study } & Rep. age & 37 & 18.5 & \multirow{4}{*}{$\begin{array}{c}\mathrm{FEPT}^{(* *)} \\
\mathrm{P}=0.704 \\
\mathrm{NS}\end{array}$} \\
\hline & & Post-rep. age & 163 & 81.5 & \\
\hline & \multirow{2}{*}{ Control } & Rep. age & 40 & 20 & \\
\hline & & Post-rep. age & 160 & 80 & \\
\hline \multirow{4}{*}{ Breast feeding } & \multirow{2}{*}{ Study } & Yes & 125 & 62.5 & \multirow{4}{*}{$\begin{array}{c}\text { FEPT } \\
P=0.000 \\
H S\end{array}$} \\
\hline & & No & 45 & 22.5 & \\
\hline & \multirow{2}{*}{ Control } & Yes & 151 & 75.5 & \\
\hline & & No & 17 & 8.5 & \\
\hline \multirow{8}{*}{$\begin{array}{l}\text { The use of } \\
\text { contraception }\end{array}$} & \multirow{8}{*}{ Control } & Not use & 76 & 38 & \multirow{8}{*}{$\begin{array}{c}\chi^{2}=7.179 \\
P=0.066 \\
\text { NS }\end{array}$} \\
\hline & & Pills & 67 & 33.5 & \\
\hline & & Helix & 28 & 14 & \\
\hline & & Surgery & 20 & 10 & \\
\hline & & Not use & 93 & 46.5 & \\
\hline & & Pills & 46 & 23 & \\
\hline & & Helix & 41 & 20.5 & \\
\hline & & Surgery & 20 & 10 & \\
\hline
\end{tabular}

C.S.: comparisons significant; FEPT: Fisher exact probability test.

Table 3. Descriptive statistics related to some reproductive characteristics in both groups

\begin{tabular}{lccccc}
\hline Reproductive characteristics & Groups & No. & M.S. & Std. dev. & Std. error mean \\
\hline \multirow{2}{*}{ Age at menarche } & Study & 200 & 12.48 & 0.81 & 0.06 \\
& Control & 200 & 12.59 & 0.83 & 0.06 \\
\hline \multirow{2}{*}{ Age at first pregnancy } & Study & 170 & 27.01 & 11.81 & 0.08 \\
& Control & 168 & 23.53 & 11.52 & 0.08 \\
\hline \multirow{2}{*}{ Pregnancy interval } & Study & 170 & 1.32 & 0.72 & 5.10 \\
& Control & 168 & 1.20 & 0.69 & 4.92 \\
\hline \multirow{2}{*}{ Age at menopause } & Study & 112 & 52.90 & 1.97 & 0.19 \\
& Control & 112 & 52.54 & 1.92 & 0.18 \\
\multirow{2}{*}{ Age at last menstrual cycle } & Study & 112 & 56.81 & 42.30 & 4.00 \\
& Control & 112 & 56.54 & 42.32 & 4.00 \\
\hline \multirow{2}{*}{ Duration of pills contraception } & Study & 130 & 7.44 & 1.70 & 0.15 \\
& Control & 125 & 7.03 & 2.00 & 0.18 \\
\hline
\end{tabular}

C.S.: comparisons significant; M.S.: mean of score. the age at menarche for control group, $12.59 \pm 0.83$ years. The mean age at first pregnancy $27.01 \pm 11.81$ years was noted for study sample, while $23.53 \pm$ 11.52 years for the control group. Pregnancy interval mean was $1.32 \pm$ 0.72 years for study sample, and $1.20 \pm$ 0.69 years for control. Age at menopause was $52.90 \pm 1.97$ years for study sample and $52.54 \pm 1.92$ years for control. The mean age at last menstrual cycle was $56.81 \pm 42.30$ years for study sample and $56.54 \pm 42.32$ years for control, and regarding the duration of contraception use, $7.44 \pm 1.70$ years for the study group and $7.03 \pm 2.00$ years for the control.

Table 4 shows that the majority $(60 \%)$ of cases had third stage of breast cancer, $52 \%$ of cases had left breast cancer, $93 \%$ of cases had no family history, and $51 \%$ of cases had 3-4 years period of breast cancer. High significant differences were found between breast cancer stages, breast cancer side and period of breast cancer, while no significant differences were found in family history.

Table 5 shows the results of testing coincidence's responding between the difference of the studied groups according to sub and main domains of "Life style to Breast Cancer in Women" through equality of variances and equality of mean value parameters. The results of testing indicated that highly significant differences at $\mathrm{P}<0.001$ were obtained (Fig. 1).

Table 6 shows significant differences between study and control group in items (Do Exercise at least $20 \mathrm{sec}$ or more 3 times weekly, and I walk whenever possible). Regarding nutritional aspects the results shows low mean scores in majority of items and low RS and assessed failure for both study and control groups, except items 3, 4,5, 6 and 12 for study group, and the items 3, 4, 5, 6, 11 \& 12 for control group with high RS, and assessed pass. There are significant differences between the study and control group in items 1, 5, 6, 7 and 11 .

The results from Table 7 has reported that the distribution of the life style to breast cancer in women through the two dichotomous of responding had no relationship with their demographical characteristics variables and as well as of some related variables (reproductive characteristics) with the overall assessments at the study group except with interval between pregnancies and duration of contraception only and we can 
Table 4. Distribution of the study sample according to breast cancer history

\begin{tabular}{|c|c|c|c|c|c|}
\hline About breast cancer & Stage & Freq. & Percent & $\begin{array}{l}\text { Cum. } \\
\text { percent }\end{array}$ & C.S. \\
\hline \multirow{4}{*}{ Breast cancer stage } & Stage 1 & 8 & 4 & 4 & \multirow{4}{*}{$\begin{array}{c}\chi^{2}=187.36 \\
P=0.000 \\
H S\end{array}$} \\
\hline & Stage 2 & 70 & 35 & 39 & \\
\hline & Stage 3 & 120 & 60 & 99 & \\
\hline & Stage 4 & 2 & 1 & 100 & \\
\hline \multirow{3}{*}{ Breast cancer side } & Right & 94 & 47 & 47 & \multirow{3}{*}{$\begin{array}{c}\chi^{2}=94.840 \\
P=0.000 \\
H S\end{array}$} \\
\hline & Left & 104 & 52 & 99 & \\
\hline & Both of them & 2 & 1 & 100 & \\
\hline \multirow{6}{*}{ Family history } & Non applicable & 186 & 93 & 93 & \multirow{6}{*}{$\begin{array}{c}\chi^{2}=3.143 \\
P=0.534 \\
\text { NS }\end{array}$} \\
\hline & Mother & 5 & 2.5 & 95.5 & \\
\hline & Sister & 3 & 1.5 & 97 & \\
\hline & Daughter & 1 & 0.5 & 97.5 & \\
\hline & Aunt & 3 & 1.5 & 99 & \\
\hline & Grandma & 2 & 1 & 100 & \\
\hline \multirow{4}{*}{ Period of disease in years } & $1-2$ & 45 & 22.5 & 22.5 & \multirow{4}{*}{$\begin{array}{c}\chi^{2}=94.070 \\
P=0.000 \\
H S\end{array}$} \\
\hline & $3-4$ & 102 & 51 & 73.5 & \\
\hline & $5-6$ & 51 & 25.5 & 99 & \\
\hline & 7 and more & 2 & 1 & 100 & \\
\hline
\end{tabular}

C.S.: comparisons significant; NS: non sig. at $\mathrm{P}>0.05$; HS: highly sig. at $\mathrm{P}<0.01$.

Table 5. Comparisons significant for the studied sub and main domains of "life style to breast cancer in women" between study and control groups

\begin{tabular}{|c|c|c|c|c|c|c|}
\hline \multirow[t]{2}{*}{ Sub and main domains } & \multicolumn{2}{|c|}{$\begin{array}{c}\text { Levene's test for } \\
\text { equality of variances }\end{array}$} & \multicolumn{3}{|c|}{ t-test for equality of means } & \multirow[t]{2}{*}{ C.S. } \\
\hline & $\begin{array}{c}(\mathbf{F}) \\
\text { Statistic }\end{array}$ & Sig. & $\begin{array}{c}(\mathbf{t}) \\
\text { Statistic }\end{array}$ & d.f. & $\begin{array}{c}\text { Sig. } \\
\text { (2-tailed) }\end{array}$ & \\
\hline Exercise & 4.385 & 0.037 & -4.878 & 390.5 & 0.000 & $\mathrm{HS}$ \\
\hline Nutrition & 0.161 & 0.688 & -4.272 & 398.0 & 0.000 & $\mathrm{HS}$ \\
\hline $\begin{array}{l}\text { Life style for exercise } \\
\text { and nutrition }\end{array}$ & 0.692 & 0.406 & -6.405 & 398.0 & 0.000 & $\mathrm{HS}$ \\
\hline
\end{tabular}

C.S.: comparisons significant; NS: non sig. at $P>0.05$; HS: highly sig. at $P<0.01$. conclude that the studied questionnaire can be amended for all individuals of the population concerning with breast cancer irrespective of the differences in their demographical and reproductive characteristic variables.

\section{Discussion}

The age group, 50-54 years, was the larger group $(39.5 \%)$ in comparison with the other age groups for both study and control groups. Their ages ranged between 22 and 83 years with mean \pm SD of $53.19 \pm 6.48$ years for study group, while the mean \pm SD of control group was $50.99 \pm 9.05$ years. This study was in agreement with study conducted by Benz $2009^{6}$ who stated that up to $80 \%$ of breast cancers occur after 50 years. The National Cancer Institute (2010) reports that more than three-quarters of breast cancer cases occur in women over age 50 years and stated that the risk of getting breast cancer increases with age. Regarding BMI, the majority (44.5\%) of study had overweight (25$29.9 \mathrm{~kg} / \mathrm{m}^{2}$ ), while $48.5 \%$ of control group had normal weight (18.5-24.9 $\mathrm{kg} /$ $\mathrm{m}^{2}$ ). In addition to that, BMI reported a highly significant difference at $\mathrm{P}<0.01$, with bad assessment at the study group compared with the control. Buist and Adiana $(2003)^{8}$ have indicated that their study looked at the relationship between tumor growth and BMI, an indicator of obesity that is based on a person's height and weight. Understanding how BMI is related to tumor growth could provide

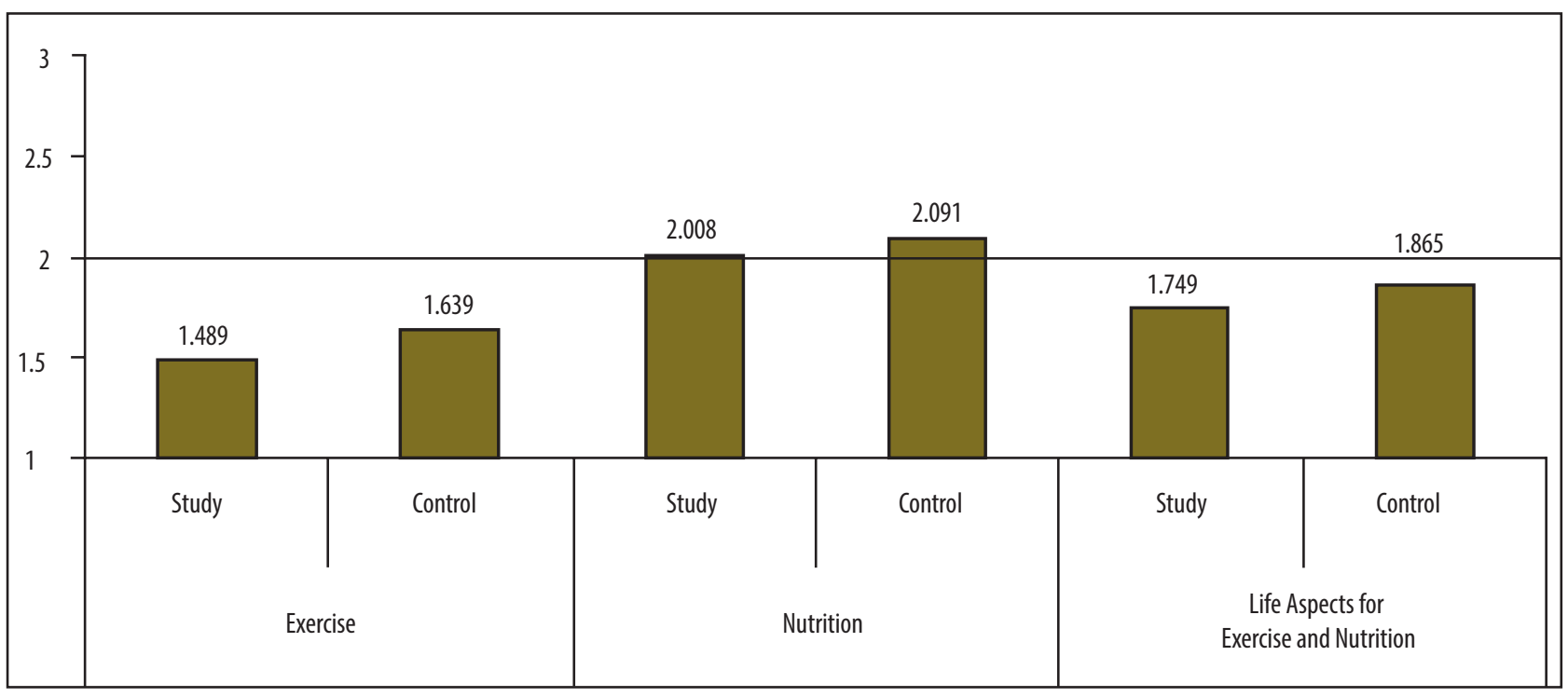

Fig. 1 Bar chart for mean of score at the sub and main domain of life aspects (exercise and nutrition) at the study and control groups. 
Table 6. Descriptive statistics (mean of score, standard deviation, relative sufficiency and assessment of items according to the scale's cutoff point) for the studied questionnaire's life style to breast cancer in women in the two groups

\begin{tabular}{|c|c|c|c|c|c|c|c|c|}
\hline \multirow[t]{2}{*}{ Items } & \multicolumn{3}{|c|}{ Study } & \multicolumn{3}{|c|}{ Control } & \multirow[t]{2}{*}{$P$ value } & \multirow[t]{2}{*}{ C.S. $(*)$} \\
\hline & M.S. & Std. Dev. & R.S. $\%$ & M.S. & Std. Dev. & R.S. $\%$ & & \\
\hline \multicolumn{9}{|l|}{ Exercise } \\
\hline 1. Do exercise at least 20 sec or more, 3 times weekly & 1.06 & 0.23 & 35 & 1.14 & 0.40 & 38 & 0.029 & $S$ \\
\hline 2. Stop exercise when you feel fatigue & 1.11 & 0.46 & 37 & 1.18 & 0.54 & 39 & 0.055 & NS \\
\hline 3. My job needs for walking & 1.31 & 0.70 & 44 & 1.34 & 0.71 & 45 & 0.563 & NS \\
\hline 4. My work is to exercise inside the house & 2.42 & 0.76 & 81 & 2.56 & 0.71 & 85 & 0.052 & NS \\
\hline 5. I walk wherever possible & 1.55 & 0.69 & 52 & 1.98 & 0.87 & 66 & 0.000 & HS \\
\hline \multicolumn{9}{|l|}{ Nutrition } \\
\hline 1. When I choose animal protein I choose fish & 1.72 & 0.80 & 57 & 1.95 & 0.88 & 65 & 0.010 & $S$ \\
\hline 2. I eat the chest of a chicken without skin & 1.73 & 0.87 & 58 & 1.79 & 0.88 & 60 & 0.391 & NS \\
\hline 3. I eat red meat free of fat once a week & 2.00 & 0.73 & 67 & 2.05 & 0.72 & 68 & 0.494 & NS \\
\hline 4. Decreasing the use of solid animal fats or butter when cooking & 2.24 & 0.73 & 75 & 2.24 & 0.68 & 75 & 0.829 & NS \\
\hline 5. Use vegetable oils such as corn oil, olive oil, etc. & 2.50 & 0.62 & 83 & 2.64 & 0.53 & 88 & 0.019 & S \\
\hline 6. When I choose vegetarian protein I choose legumes & 3.00 & 0.00 & 100 & 2.98 & 0.14 & 99 & 0.045 & S \\
\hline 7. I eat non-cooked vegetables, 2.5 cups a day & 1.32 & 0.53 & 44 & 1.47 & 0.61 & 49 & 0.007 & HS \\
\hline 8. I eat 5 pieces of fresh fruit per day & 1.20 & 0.43 & 40 & 1.27 & 0.50 & 42 & 0.166 & NS \\
\hline 9. I eat sweets and sugars per day & 1.96 & 0.91 & 65 & 1.88 & 0.87 & 63 & 0.392 & NS \\
\hline 10. I drink adequate fluids (8 glasses of water or 2.5 litres per day) & 1.86 & 0.77 & 62 & 1.93 & 0.81 & 64 & 0.401 & NS \\
\hline 11. I use yogurts low or free in fat & 1.89 & 0.85 & 63 & 2.08 & 0.88 & 69 & 0.029 & S \\
\hline 12. Refrained from eating irregular meals & 2.17 & 0.90 & 72 & 2.10 & 0.92 & 70 & 0.458 & NS \\
\hline 13. Eating a daily multivitamin & 1.87 & 0.88 & 62 & 1.97 & 0.91 & 66 & 0.230 & NS \\
\hline 14. I adopted canned foods & 1.40 & 0.69 & 47 & 1.31 & 0.59 & 44 & 0.313 & NS \\
\hline
\end{tabular}

C.S.: comparisons significant; NS: non sig. at $\mathrm{P}>0.05$; HS: highly sig. at $\mathrm{P}<0.01$.

Table 7. Association among demographical and reproductive variables with overall assessments in life style among women with breast cancer

\begin{tabular}{lcccccccc}
\hline Predicted variables & \multicolumn{3}{c}{ Study } & & \multicolumn{3}{c}{ Control } \\
\cline { 2 - 3 } & C.C. & P value & & & C.C. & P value & \\
\hline Age & 0.135 & 0.881 & NS & & 0.251 & 0.098 & NS \\
BMl: kg/m & 0.155 & 0.176 & NS & & 0.111 & 0.475 & NS \\
Marital status & 0.078 & 0.873 & NS & & 0.210 & 0.056 & NS \\
Family income & 0.147 & 0.111 & NS & & 0.201 & 0.015 & S \\
Gravidity & 0.164 & 0.583 & NS & & 0.281 & 0.025 & S \\
Parity & 0.128 & 0.831 & NS & & 0.266 & 0.047 & S \\
Age at menarche & 0.075 & 0.887 & NS & & 0.170 & 0.204 & NS \\
Age at first pregnancy & 0.132 & 0.698 & NS & & 0.158 & 0.507 & NS \\
Interval between pregnancies & 0.169 & 0.025 & S & & 0.025 & 0.744 & NS \\
Age at menopause & 0.328 & 0.096 & NS & & 0.280 & 0.393 & NS \\
Age at last menstrual cycle & 0.326 & 0.205 & NS & & 0.265 & 0.582 & NS \\
Reproductive age & 0.021 & 0.765 & NS & & 0.079 & 0.263 & NS \\
Breast feeding & 0.076 & 0.317 & NS & & 0.038 & 0.620 & NS \\
The use of contraception & 0.081 & 0.838 & NS & & 0.157 & 0.369 & NS \\
Duration of contraception use & 0.355 & 0.028 & S & 0.360 & 0.029 & S \\
\hline
\end{tabular}

critical tools to assist clinicians with preand post-diagnostic breast cancer surveillance and would help clarify the role BMI plays as a predictor of recurrence and death from breast cancer. The findings of the current study was in agreement with the findings of Perez $(2010)^{9}$ who indicated that a mid-life increase in BMI may substantially increase postmenopausal breast cancer risk, according to research by investigators from NCI and Columbia University's Mailman School of Public Health. In a recent analysis, women who reported a gain in BMI of five points $\left(5 \mathrm{~kg} / \mathrm{m}^{2}\right)$ or more between age 20 and postmenopausal age (55-74 years) had nearly twice the risk of developing postmenopausal breast cancer compared to women who maintained their BMI during the same time period. In addition, researchers found independent positive associations between postmenopausal breast cancer and BMI gain both before and after age 50 years. Regarding marital status, $70.5 \%$ of study and $66.5 \%$ of control group were married. Khan et al. $(2002)^{10}$ said that the previous studies have found that married women are more likely to be diagnosed at an earlier stage of cancer than those who are unmarried. But Randi et al. (2004) ${ }^{11}$ said that our study suggests that marital status is not materially associated with cancer risk. Thus, the evidence that married subjects are at lower risk of several other major diseases may not be applicable to cancer. Regarding family income, $42.5 \%$ and $47 \%$, respectively for both groups have sufficient income, while the highest proportion was with their insufficient income. This result refers to the fact that the sample is from the low- and 
middle-income class. March (2002) ${ }^{12}$ said that a new study adds to mounting evidence that women with lower incomes and less education are more likely to be diagnosed with advanced breast cancer than women with higher socioeconomic standard. Curado and others $(2007)^{13}$ stated that the recent media reports have highlighted the increasing incidence of breast cancer in low- and middle-income countries. The relative risk of breast cancer diagnosis associated with current and recent use of hormonal contraceptives did not appear to vary with family history of breast cancer. ${ }^{14}$ Some studies have suggested that women who began using hormonal contraceptives before the age of 20 or before their first full-term pregnancy are at increased risk for breast cancer, but it is not clear how much of the risk stems from early age at first use, and how much stems from use before the first full-term pregnancy. ${ }^{15}$

Regarding the effect of exercise and nutrition on breast cancer occurrence the results of testing indicated that highly significant differences at $\mathrm{P}<0.001$ were obtained. American Cancer Society stated that many studies have shown that moderate to vigorous physical activity is linked with lower breast cancer risk. ${ }^{16} \mathrm{~A}$ diet that is rich in vegetables, fruits, poultry, fish and low-fat dairy products has also been linked with a lower risk of breast cancer in some studies. But it is not clear if specific vegetables, fruits or other foods can lower risk. Research has shown that poor diet and not being active are two key factors that can increase a person's cancer risk. ${ }^{17}$

\section{Conclusion}

The present study shows the highest percentage of women having breast cancer was of age group 50-54 years, overweight $25-29.9 \mathrm{~kg} / \mathrm{m}^{2}$, secondary school graduated, married and having sufficient family income. The results indicated that the individuals of the study groups reported no significant differences were found in family history while highly significant differences of women were breast feeding their babies. The study also showed that the sub and main domain of life style for exercise and nutrition reported a highly significant difference at
$\mathrm{P}<0.01$. The results of testing indicated that a significant difference at $\mathrm{P}<0.05$ was obtained at the related variables (reproductive characteristics) with the overall assessments at the study group except with interval between pregnancies and duration of contraception only.

\section{Recommendations}

1. Activation of media and Ministry of Health role for increasing the awareness of women and their families about the importance of reducing the risk factors which contributing on breast cancer occurrence through.

a. Monthly breast self-examination and regular mammography for age $\geq 40$ years are the recommended methods of early detection of breast cancer.

b. At least 8 hours sleep daily.

c. Exercising regularly for least 1 hour 3 times a week.

d. Encourage the women about healthy diet and nutrition.

e. Encourage breast feeding and maintaining a healthy weight.

2. Further study on large population.

\section{References}

1. Simms K. Exercise and nutrition: coping mechanisms for life. Fully Living. April 16: 2011

2. Ray L. Nutrition and exercise for the elderly. National Institute on Aging: Exercise \& Physical Activity. Sep 30;2010.

3. Breast Cancer Research Program. Environmental influences and breast cancer. University of California; 2002.

4. Lauren E. McCullough, Sybil M. Eng, PatrickT. Bradshaw, Rebecca J. Cleveland, Susan L. Teitelbaum, Alfred I. Neugut, et al. Fat or fit: the joint effects of physical activity, weight gain, and body size on breast cancer risk. Cancer. 2012 Jun 25;118(19):4860-8. doi: http://dx.doi.org/10.1002/cncr.27433

5. Breastcancer.org: Nutrition and Breast Cancer Risk Reduction. 17 Sept 2012.

6. Benz CC. Impact of age on the biology of breast cancer. Cancer and Developmental Therapeutics Program Buck Institute for Age Research Adjunct Professor. San Francisco: University of California; 2009. pp 9-10.

7. National Cancer Institute: What you need to know about breast cancer? 2010

8. Buist D, Diana S. Optimizing breast cancer outcomes: BMI, tumor markers, and quality of care. American Cancer Society; 2003

9. Perez V. Gain in body mass index increases postmenopausal breast cancer risk. 20 April, 2010.
10. Khan S, et al. Association between marital status and stage at diagnosis of breast cancer: what role does screening play? University of Texas Medical Branch, 11 Nov 2002.

11. Randi G, Altieri A, Gallus S, Chatenoud L, Montella M, Franceschi S, et al. Marital status and cancer risk in Italy. Prev Med. 2004 May;38(5):523-8.

12. March D. Researcher find educational level/income increase risk of advanced breast cancer diagnosis; 2002.

13. Curado MP, Edwards B, Shin HR, et al. Cancer incidence in five continents. France: International Agency for Research on Cancer, Vol. IX. Lyon, 27 Dec 2007.

14. National Cancer Institute: "Hormone Therapy". Genetics of breast and ovarian cancer. 12 Aug 2006.

15. World Health Organization International Agency for Research on Cancer (1999). "Hormonal Contraception and Post-menopausal Hormonal Therapy," Retrieved 12 Mar 2011; 1999

16. American cancer society: Diet and activity factors that affect risks for certain cancers. Breast cancer; 2014.

17. American Cancer Society. Diet and physical activity: What's the cancer connection? 2014. 